\title{
Early menarche and its consequence in Korean female: reducing fructose intake could be one solution
}

\author{
Ji Hyun Kim, MD, PhD ${ }^{1}$, Jung Sub Lim, MD, PhD ${ }^{2}$ \\ ${ }^{1}$ Department of Pediatrics, Dongguk University Ilsan Hospital, Goyang, Korea; ${ }^{2}$ Department of Pediatrics, Korea Cancer Center Hospital, Seoul, Korea
}

The mean age at menarche (AAM) of Korean females has been rapidly decreasing over the last 50 years; currently, the prevalence of early menarche ( $<12$ years) is $22.3 \%$. Female adolescents who experience early menarche are known to be at greater risk of psychosocial and behavioral problems along with several physical health problems such as menstrual problems. They also tend to achieve a shorter final height and develop obesity. Population-based Korean studies have shown a strong association between early menarche and the risk of obesity, insulin resistance, metabolic syndrome, nonalcoholic fatty liver disease, diabetes, breast cancer, and cardiovascular disease in adulthood. Although the exact mechanism of how early menarche causes cardiometabolic derangement in later adulthood is unknown, childhood obesity and insulin resistance might be major contributors. Recent studies demonstrated that an excessive consumption of fructose might underlie the development of obesity and insulin resistance along with an earlier AAM. A positive association was observed between sugar-sweetened beverages (a major source of fructose) intake and obesity, metabolic syndrome, insulin resistance, and cardiometabolic risk in Korean females. In pediatrics, establishing risk factors is important in preventing disease in later life. In this regard, early menarche is a simple and good marker for the management of cardiometabolic diseases in adulthood. Decreasing one's fructose intake might prevent early menarche as well as the development of obesity, insulin resistance, and cardiometabolic diseases.

Key words: Menarche, Metabolic disease, Fructose, Insulin resistance, Obesity, Pathophysiology

\section{Key message}

In Korea, the average age of menarche has declined sharply. Early menarche is associated with psychosocial and behavioral problems and cardiometabolic disease. Excess fructose intake has been suggested as one cause of early menarche in recent studies, so reducing fructose intake may be one solution.

\section{Introduction}

Menarche, defined as a young woman's first menstrual period, is a landmark of pubertal development in females. Age at menarche (AAM) is a key maturity indicator of a female's healthy transition from childhood into young adulthood and an important clinical indicator of her physical, nutritional, and reproductive health. ${ }^{1)}$ AAM is influenced by several factors, including genetics, ethnicity, geography, socioeconomic status, and nutritional status. ${ }^{2-4)}$

AAM has decreased continuously and rapidly in Asian countries, including Korea, probably because of improvements in nutrition. ${ }^{5)}$ In Korea, AAM has declined from 15-17 years in the 1960 s to around 14 years in the 1980s and 12.6 years in the 1990s. ${ }^{5)}$ Thus, the proportion of females with early menarche, commonly defined as an AAM $<12$ years old, has also increased in Korea. ${ }^{6}$

Female adolescents who experience early puberty and early menarche are known to be at a greater risk of psychosocial problems such as delinquency and risky sexual behavior. ${ }^{7)}$ Furthermore, they achieve a shorter final height and develop obesity and several physical health problems such as menstrual problems, compared to adolescents who experience menarche at a later age. ${ }^{8,9)}$ Furthermore, early menarche is a well-known risk factor of chronic cardiometabolic disease and related early mortality in adulthood. ${ }^{10)}$ Population-based Korean studies also showed an association between early AAM ( $<12$ years) and the risk of obesity, insulin resistance (IR), metabolic syndrome (MetS), nonalcoholic fatty liver disease (NAFLD), diabetes, breast cancer, and cardiovascular disease (CVD) in adulthood. ${ }^{10-13)}$

In pediatrics, establishing risk factors is important in disease prevention in later life. An early AAM can be a good marker for predicting future metabolic problems. Therefore, this review aimed to: (1) review the secular trend of AAM and early menarche in Korean females; (2) review the factors and conditions related to AAM; (3) find proof of whether early menarche is a risk factor for obesity, IR, MetS, NAFLD, diabetes, and cancer in adult Korean females; and (4) address how to prevent early menarche and discuss its consequences by reviewing its

Corresponding author: Jung Sub Lim, PhD, MD. Department of Pediatrics, Korea Cancer Center Hospital, 75 Nowon-ro, Nowon-gu, Seoul 01812, Korea 凶E-mail: limjs@kcch.re.kr, https://orcid.org/0000-0001-9560-8921

Received: 17 April, 2019, Revised: 27 December, 2019, Accepted: 28 February, 2020

This is an open-access article distributed under the terms of the Creative Commons Attribution Non-Commercial License (http://creativecommons.org/licenses/bync/4.0/) which permits unrestricted non-commercial use, distribution, and reproduction in any medium, provided the original work is properly cited.

Copyright (c) 2021 by The Korean Pediatric Society 
proposed mechanism. To this end, we reviewed the literature, particularly meta-analyses and prospective studies, regarding menarche in Korean female. We hope this review will help pediatricians comprehensively understand the lifetime health problems of women due to early menarche and in preventing early menarche and its complications.

\section{Secular trends in pubertal timing and AAM}

Breast budding is the herald of puberty in girls. The age at the onset of breast development seems to have declined markedly over the last two decades. ${ }^{14)}$ Before the 1980s, the mean age at the onset of breast development was approximately 11 years in American and European countries. ${ }^{15)}$ However, the mean age at puberty onset in girls was $<10$ years from the 3rd National Health and Nutrition Examination Survey (NHANES III), 1988-1994. ${ }^{16}$

A gradual decline in AAM was reported over the past few decades in Western countries. ${ }^{17)}$ In Europe, the AAM decreased from approximately 17 years in the early 19th century to approximately 13 years by the mid-20th century and stayed relatively stable with a variation of 0.5 years depending on study population since the 1960s. ${ }^{18)}$ However, this secular trend is rapid and ongoing in Asian countries, including Korea. In China, the AAM has fallen 0.7 years per decade over a 40 -year period; most recently, it was 12.76 years. ${ }^{19)}$

In Korea, the mean AAM for females born in 1925-1929 was $16.59 \pm 1.82$ years. The AAM decreased to $13.11 \pm 1.52$ years for those born in 1980-1984 and to $12.60 \pm 1.14$ years for those born in 1990-1994 (Fig. 1). ${ }^{5)}$ Young Korean women aged $18-30$ years now have a mean AAM of $12.7 \pm 1.6$ years, which is 1.5 years earlier than that of their mothers. Furthermore, the prevalence of early menarche ( $<12$ years) is $22.3 \%$, while the percentage of subjects' mothers with early menarche was only

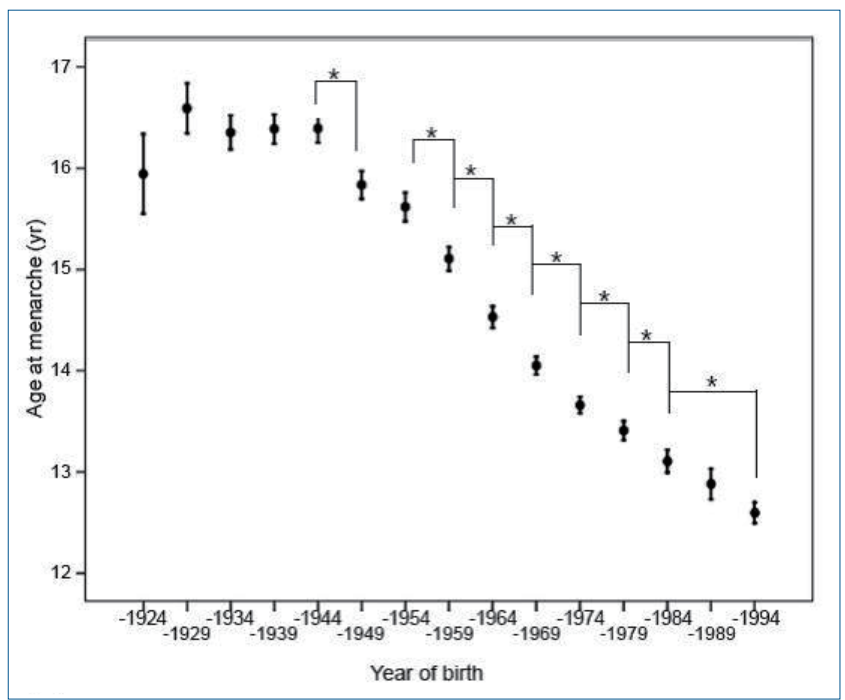

Fig. 1. Secular trend of mean age at menarche and body mass index for women born between 1904 and 1995. Adapted from Ahn et al. Ann Pediatr Endocrinol Metab 2013;18:60-4.
$2.5 \%{ }^{8}{ }^{8}$ This trend might be due to changes in the socioeconomic environment, possibly acting through changes in nutrition and exercise patterns. South Koreans rapidly accepted Western culture, especially the Western diet, after the 1988 Olympic Games. On the contrary, North Korean refugees still showed an AAM around $16.0 \pm 2.1$ years. ${ }^{20)}$

\section{Determinants and risk factors of early menarche}

The AAM can be determined by genetic and environmental factors and their interactions. However, the observed secular trend in AAM in this ethnicity may suggest that environmental rather than genetic factors are the major contributors to increasing rates of early menarche. The factors and conditions related to early menarche are listed in Table 1.

\section{Genetic determinants of menarche}

Twin and familial studies of AAM indicated a $57 \%-82 \%$ of variance in the timing of puberty could be explained by heritable factors. ${ }^{21,22)}$ Racial differences in pubertal maturation might reflect genetic factors.

Genome-wide association studies on AAM performed in Caucasian females confirmed associations at two loci: 6q21 (in or near the LIN28B gene) and 9q31.2.23,24) Effect sizes were estimated at only 0.12 years earlier per effect allele for LIN28B and $9 \mathrm{q} 31.2$. Menarche signals were enriched in imprinted regions, with three loci (DLK1-WDR25, MKRN3-MAGEL2, and KCNK9).25)

Recently, a woman's AAM has been suggested as a likely contributor to earlier pubertal development and early menarche in her female offspring. ${ }^{26)}$ In our study of Korean mother-daughter pairs, the correlation between the AAM of mothers and their daughters was 0.245 , comparable to figures of $0.23-0.39$ in other countries. ${ }^{27,28)}$ Furthermore, the daughters of mothers with an earlier AAM ( $<13$ years) were more likely to experience early menarche ( $<12$ years) themselves (earlier, $35.6 \%$; reference, $25.8 \% ; P<0.05)$. The odds ratio (OR) for early menarche of such daughters compared with reference was 1.56 after the adjustment for confounders (under review).

Table 1. Factors and conditions related to early menarche

\begin{tabular}{ll}
\hline Genetic & \multicolumn{1}{c}{ Nongenetic } \\
\hline Race & Obesity \\
LIN28B & Sugar-sweetened beverages (fructose) \\
$D L K 1-W D R 25$ & Low intake of fiber \\
MKRN3-MAGEL2 & Decreased physical activity \\
KCNK9 & Endocrine-disruptor chemicals \\
Mother's earlier menarche & Small for gestational age \\
& Rapid early weight gain \\
& Precocious puberty \\
\hline
\end{tabular}




\section{Nongenetic determinants of menarche}

Despite the major role of genetic factors in AAM, environmental factors have gained increasing attention due to their potential for control. It is well-known that AAM is related to obesity, nutrition (especially fructose), endocrine-disruptor channels (EDCs), and physical activity. Furthermore, small for gestational age (SGA) and precocious puberty are risk factors for early menarche.

\section{1) Obesity (body fat)}

The "critical weight hypothesis" suggested by Frisch-Revelle states that the onset of menarche is associated with increased body fat, $22 \%$ or $48 \mathrm{~kg}$ of body weight, in pubertal girls. ${ }^{29}$ ) Leptin conveys information about fat mass and distribution to the hypothalamus during puberty. ${ }^{30)}$ It stimulates the pulsatile release of gonadotropin-releasing hormone $(\mathrm{GnRH})$ in the hypothalamus, which serves as a signal for the onset of menarche. ${ }^{31)}$ Most studies showed the association between high-fat content in infancy (or prepuberty or puberty) and earlier AAM. A higher subcutaneous fat levels and a high prepubertal body mass index (BMI) are associated with an increased likelihood of early ( $<11$ years) menarche. ${ }^{3)}$

\section{2) Nutritional habits}

An increased energy intake was associated with early menarche. Food quality also influences puberty. Formula feeding during early infancy might promote weight gain and earlier AAM in Asians and Caucasians, ${ }^{32,33)}$ whereas breastfeeding may decrease the risk of early puberty. However, recent studies found no association between milk consumption, breastfeeding duration (more than 3 months), and pubertal timing in Chinese children. ${ }^{34)}$ Berkey et al. ${ }^{35)}$ demonstrated that a high animal versus vegetable protein ratio at the ages of 3-5 years is associated with early menarche after controlling for BMI. Dietary fiber might prevent early AAM through its effect on estrogen metabolism. ${ }^{36}$ Dietary fiber might reduce estrogen reabsorption and deconjugation in the gut.

\section{3) Sugar-sweetened beverages}

Sugar-sweetened beverages (SSBs) include sodas and soft drinks as well as other beverages with added sugars such as fruit-flavored drinks, sports and energy drinks, and sweetened coffees and teas. SSBs comprise approximately 30\% of the fructose consumed in the US diet. ${ }^{37)}$ SSBs caused early AAM in a prospective study of US girls. ${ }^{38)}$ Girls consuming $>1.5$ SSBs per day had an estimated 2.7-month younger AAM. The National Heart, Lung, and Blood Institute Growth and Health Study recruited 2,379 girls aged 9-10 years and followed them for 10 years. The incidence of early menarche (menarche age $<11$ years) occurred in $8.3 \%$ of the girls. After the adjustment for confounders and premenarcheal percentage body fat, a greater consumption of SSBs was associated with a higher risk of early menarche. ${ }^{39)}$ The relative risk (RR) for one serving/day was 1.47.

\section{4) Exercise}

Some physical activities, in combination with a nutritional deficiency, may influence the onset of puberty ${ }^{40)}$ and lead to a mean 1-year delay in AAM in Caucasians. ${ }^{41)} \mathrm{AAM}$ was positively associated with physical activity (at least 2 hours daily) in a group of Colombian university women. ${ }^{42}$ Menarche tends to occur later in athletes, including ballet dancers, then in the general population, but not in swimmers, suggesting that intense exercise delays puberty. ${ }^{43)}$ The most probable explanation for the lack of a pubertal delay in swimmers is that the normal body fat composition of swimmers balances the negative hypothalamic effect on GnRH pulsatile exerted by intensive exercise.

\section{5) Endocrine-disruptor chemicals}

EDCs are a group of hormonally active agents. People are directly or indirectly exposed to EDCs every day because EDCs are widely used in the industry for almost a century. ${ }^{44)}$ EDCs are used as industrial solvents/lubricants (polychlorinated biphenyls [PCBs], polybrominated biphenyls, dioxins), plastics (bisphenol A [BPA]), plasticizers (phthalates), and pesticides (dichlorodiph enyltrichloroethane). ${ }^{45)}$ Phthalates and PCBs are associated with earlier breast development and menarche, respectively. ${ }^{46)} \mathrm{BPA}$ is well-known for its molecular estrogen-like actions and showed a close relationship between urinary BPA, body weight, and early puberty. ${ }^{47)}$ Low doses of lead may be associated with the earlier onset of menses, whereas high-dose exposure may delay AAM. ${ }^{41)}$ Some personal care chemicals, such as hair care products, used every day during childhood, can also lower AAM. ${ }^{48)}$

\section{6) SGA and rapid early weight gain}

Girls born SGA showed early pubertal onset and menarche by about $5-10$ months. ${ }^{49)} \mathrm{A}$ lower postnatal weight gain has a stronger association with earlier AAM in females with intrauterine growth retardation. A rapid early infancy weight gain from birth to age 2 months as well as $2-9$ months predicted subsequent greater adiposity and earlier AAM in girls. ${ }^{32)}$

\section{7) Precocious puberty}

Precocious puberty is defined as the development of secondary sexual characteristics before 8 years of age in girls. Premature activation of the hypothalamic-pituitary-gonadal axis in central precocious puberty stimulates the production of sex steroids that stimulate linear growth and accelerate bone age advancement and result in early menarche. In untreated children with central precocious puberty, early growth acceleration and premature fusion of the epiphyseal growth plates result in an impaired final height. ${ }^{50,51)}$

\section{Early menarche and its adverse consequences in later life}

Several studies have established an association between early menarche and the risk of cardiometabolic diseases in adulthood. 
Table 2. Adverse consequences of early menarche in later life

Risk-taking behaviors
Psychologic problems
Short adult height
Obesity
Metabolic syndrome
Insulin resistance
Nonalcoholic fatty liver disease
Type 2 diabetes mellitus
Cardiovascular diseases
Breast cancer
Mortality
Others

The adverse consequences in later life (including late adolescents, young adults, and adults) associated with early menarche are listed in Table 2.

\section{Short adult height}

Early menarche increased the risk of adult short stature in young Korean women. According to the European Prospective Investigation into Cancer and Nutrition study, based on 286,205 women, their final height was $0.35 \mathrm{~cm}$ (range by country, 0.13 to $0.50 \mathrm{~cm}$ ) shorter when menarche occurred 1 year earlier. ${ }^{52)}$ Furthermore, a 1-year decrease in AAM decreased the standing height and leg length by 0.76 and $0.41 \mathrm{~cm}$, respectively, in the USA birth cohort. ${ }^{53}$

In Korea, we found that 1-year decrease in the AAM was associated with a $0.445 \mathrm{~cm}$ final height loss in young Korean women. ${ }^{8)}$ We also found that young women with early menarche had a $10.5 \%$ chance of having a short adult stature $(\leq 153 \mathrm{~cm})$, which was 2.62-fold higher than those with later menarche. These findings are due to the earlier closure of epiphyseal growth plates due to the increase in ovarian estrogens. ${ }^{54,55)} \mathrm{A}$ high dose of estrogen binding to its receptors in the growth plate cartilage might cause early epiphyseal fusion by advancing growth plate senescence. ${ }^{55)}$

\section{Obesity}

Obesity in adulthood is closely related with early menarche. Several studies observed an inverse relationship between AAM and adult BMI. ${ }^{56-59)}$ Although the causal relationship between AAM and obesity remains unclear, earlier menarche and obesity are strongly associated with chronic cardiometabolic diseases in adulthood.

Freedman et al. ${ }^{57)}$ advocated that increasing childhood obesity rates result in both early menarche and adulthood obesity. Girls with early menarche, including Koreans, reportedly have greater body fat content in childhood. ${ }^{20,57)}$ However, Pierce and Leon 58) stressed that earlier menarche in itself might cause obesity in adults rather than be a proxy marker of sexual maturation. The secular change of AAM was also found in normal-weight girls. ${ }^{59)}$ Menarche is accompanied by a rapid increase in body weight. ${ }^{60,61)}$ High plasma estradiol levels and low sex hormone- binding globulin (SHBG) levels due to puberty are associated with adiposity. ${ }^{62)}$ In our study based on Korea National Health and Nutrition Examination Survey (KNHANES), a younger AAM is associated with current BMI of adults after control for age. The OR of obesity in women with early menarche was 1.845 times higher than that in those who experienced menarche after 12 years. ${ }^{5)}$

\section{Metabolic syndrome}

MetS is the combination of central obesity, increased blood pressure (BP), glucose intolerance, and dyslipidemia. ${ }^{63)}$ MetS is a main target for CVD prevention, as MetS is prospectively associated with an increased risk of CVD-related morbidity and mortality in European and Asian subjects. ${ }^{63,64)}$

Early menarche is associated with MetS in most Western studies. ${ }^{65-67)}$ The Bogalusa Heart Study found that early menarche is characterized by excess body fat content and insulin in early childhood and a higher prevalence of MetS in young adulthood. ${ }^{65)}$ The KORA F4 (Cooperative Health Research in the Region of Augsburg, South Germany, 2006-2008) also showed that early menarche is associated with MetS in women aged 32-81 years; after the adjustment for age and additional confounders, including lifestyle and reproductive history, ${ }^{67)}$ that association was partially mediated by weight gain and increased BMI after 25 years of age. In our study based on KNHANESIV data, females with early menarche had a higher prevalence of central obesity, elevated fasting glucose, and elevated BP in the 20-30 years group. The OR for MetS was 3.54 in premenopausal Korean women after the adjustment for age and another confounder. ${ }^{10)}$

\section{Insulin resistance}

The role of early menarche in the development of MetS in later adulthood is uncertain. The most likely explanation is that early menarche in adolescents and MetS in adulthood are consequences of IR. Hyperinsulinemia, usually but not always accompanied by obesity, is thought to play a mediating role in the development of early puberty. ${ }^{68)}$ Hyperinsulinemia or IR independently increased the risk of MetS and coronary heart disease (CHD) risk after the adjustment for other confounders in the Helsinki Policemen Study. ${ }^{69)}$ Among Koreans, premenopausal females over 30 years of age with early menarche had a higher prevalence of central obesity and IR. ${ }^{10)}$ The OR for IR was 2.98 after the adjustment for confounders.

In pediatrics, the best example is children born SGA. In a longitudinal cohort study, SGA children had greater adiposity and IR during catch-up growth. ${ }^{70)}$ SGA girls had early puberty and a lower AAM. ${ }^{64)}$ After menarche, SGA girls also showed hyperinsulinemia, higher androgen levels, and lower SHBG levels. $^{71)}$

\section{Nonalcoholic fatty liver disease}

NAFLD is a spectrum of disease activity that ranges from simple hepatic steatosis to nonalcoholic steatohepatitis. ${ }^{72)}$ Epide. 
miological studies have shown that NAFLD may precede MetS onset and its complications and is associated with an increased risk of future CVD-related morbidity and mortality. ${ }^{73,74)}$

Mueller et al. ${ }^{75}$ first reported that earlier menarche is positively associated with NAFLD in the CARDIA study. They suggest that a 1-year earlier AAM is associated with a $10 \%$ increased the risk of NAFLD and visceral ectopic fat deposit in middle adulthood (43-55 years of age) after the adjustment for other confounders. In our study, the OR for NAFLD in Korean women with early menarche compared to reference was 3.04. Further adjustment of mediators, like obesity or IR, attenuated the association to 1.91 and 2.17, but the results remained significant. ${ }^{11)}$

\section{Type 2 diabetes mellitus}

Type 2 diabetes mellitus (T2DM) is a metabolic disorder characterized by a high blood glucose in the context of IR, a key factor in its development. ${ }^{76}$ Prospective studies showed that IR, based on Homeostatic Model Assessment of Insulin Resistance, persists for and is a powerful independent predictor of T2DM. ${ }^{77)}$ A 2.2-time increase in fasting insulin concentration was linked to a 2-fold increase in the future incidence of T2DM over a 24-year follow-up. ${ }^{78)}$

Several studies, including ours, reported that an early menarche is associated with a higher risk of T2DM..$^{79-82)}$ In the Nurses' Health Study I \& II, the RR of T2DM in the young female cohort (40-50 years) with early menarche was 1.40 versus 1.18 in the old cohort. ${ }^{79)}$ In the Atherosclerosis Risk in Communities study, the OR for diabetes was 1.41 after adjustment for adiposity and lifestyle. ${ }^{80)}$ In our study, the OR of diabetes was 3.61-fold after the adjustment for age in Korean women aged 20-50 years. ${ }^{12}$ Thus, some authors insist that the history of early menarche was a more influential factor than the current BMI or adiposity. ${ }^{81,82)}$

\section{Cardiovascular diseases}

CVD are the number one cause of death worldwide. ${ }^{83)}$ In Korea, around $22 \%$ of deaths are attributable to CVD. ${ }^{84)}$ In the past, many studies showed an association between AAM and the risk of CVD; increasing year of AAM lowers the risk of CVD. ${ }^{85-}$ 87) The UK Million Women Study and Chinese birth cohort recently reported a significant increase in CHD risk for both early and late menarche ${ }^{88,89)}$ In the UK Million Women Study, the risk of CHD was lowest at a menarcheal age of 13 years, and the risk was highest in a woman who experienced menarche at $\leq 10$ years of age with a RR of 1.27 . In Korea, a 51\% reduction in mortality associated with CHD was reported in women with early menarche ( $<17$ years) in a Kangwha cohort study. ${ }^{90)}$ The prevalence of women with a $\geq 10 \%$ or $\geq 20 \% 10$-year Framingham Coronary Heart Disease Risk Point Scale score was higher in those with early menarche ( $<13$ years) than in other groups after the adjustment for confounding factors. ${ }^{91)}$ The results were consistent with the previous meta-analysis, which reported a 3\% higher probability of death of all causes for each decreasing year of AAM. ${ }^{13)}$

\section{Cancer risk}

Breast cancer is a hormone-related cancer like ovarian and endometrial. In Korea, the incidence of breast cancer increased rapidly from 24.5 in 1999 to 50.7/100,000 in 2012 and 2nd most prevalent female cancer. ${ }^{92}$ A meta-analysis of 117 epidemiological studies showed that the breast cancer incidence risk increased by $5 \%$ when menarche occurred 1 year earlier. ${ }^{93)}$ In a meta-analysis of eight prospective endometrial cancer studies, the risk of the highest AAM was 32\% lower than that of the lowest AAM and showed that the cancer risk decreased by $4 \%$ when AAM was delayed by 2 years. ${ }^{94)}$ In Korea, women with early menarche ( $\leq 12$ years) were at increased risk of developing breast cancer with a hazard ratio of 1.57 in the Korean Heart Study. ${ }^{95)}$ Among a cohort of British women, those with early menarche ( $<12$ years) had a 1.25 -times higher cancer mortality rate and a 1.22-times higher all-cause mortality rate after the adjustment for age, BMI, and other confounders. ${ }^{96)}$

\section{Proposed mechanism of early menarche}

The exact mechanism of how early menarche contributes to the development of cardiometabolic derangement (obesity, IR, MetS, NAFLD, diabetes, breast cancer, CVD) in later adulthood is not known.

The most popular and simple explanation is that early menarche in adolescents and cardiometabolic derangement in adulthood are consequences of childhood obesity. Childhood adiposity is known to trigger puberty and, as a result, early menarche by adipocytes and related hormones. ${ }^{71,97)}$ Childhood obesity progresses to adult obesity. ${ }^{97)}$ Obesity is well-known to be closely related to IR, MetS, NAFLD, diabetes, breast cancer, and CVD. ${ }^{73,98,99)}$

The other more complex and fine explanation is that early menarche in adolescents and metabolic derangement in adulthood are consequences of IR or hyperinsulinemia. Hyperinsulinemia, which is usually but not always accompanied by obesity, is thought to play a mediating role in the development of early puberty ${ }^{66)}$ Furthermore, hyperinsulinemia or IR, accompanied by inflammation, independently increased the risk of MetS, NAFLD, T2DM, breast cancer, and CVD. ${ }^{69,77)}$ Hyperinsulinemia reduces SHBG levels, which in turn leads to greater bioavailability of the sex steroids. ${ }^{100)}$ Decreased serum SHBG levels are associated with early puberty. ${ }^{101)}$ SHBG is also a strong predictor of MetS, IR, and independent of total fat mass during puberty and might persist into adulthood. ${ }^{102)}$

\section{Decreasing fructose intake to prevent early menarche}

The next question is what causes obesity or IR. The Westernized lifestyle is associated with an increasing prevalence of obesity worldwide. The Westernized lifestyle is characterized by 
sedentary behavior or low physical activity and a Western pattern diet (WPD). The WPD is a modern dietary pattern that is generally characterized by high intakes of processed meat, pre-packaged foods, fried foods, high-fat dairy products, eggs, refined grains, potatoes, corn (and high-fructose corn syrup), and high-sugar drinks. ${ }^{133}$ In contrast, a healthy diet has higher proportions of unprocessed fruits, nuts, vegetables, whole-grain foods, poultry, and fish.

In Korea, as a result of the rapid economic growth and the adoption of a more Western lifestyle over the past four decades, the food content shifted from a traditional Korean diet (wholegrain rice, vegetables, and kimchi) to WPD (sugar, eggs, and oil). ${ }^{104)}$ Between 1998 and 2010, the consumption of sugar, sugar with coffee, and fruit intake were significantly and continuously increased. Strangely, energy intakes were significantly decreased by approximately $13 \%$ in adults over 20 years. During that period, the prevalence of obesity (BMI $\geq 25 \mathrm{~kg} / \mathrm{m}^{2}$ ) among South Korean adults also increased from $25.7 \%$ in 1998 to $37.9 \%$ in 2013. ${ }^{105)}$ Furthermore, according to the Korea Health Statistics, the percentage of obese adolescent boys and girls has increased considerably from $17.0 \%$ and $10.2 \%$ in 2005 to $19.1 \%$ and $14.3 \%$ in 2016 , respectively. $\left.{ }^{106}\right)$

A recent KNHANES study reported that SSB consumption increased dramatically from $58 \mathrm{~g} /$ day in 2008 to $101 \mathrm{~g} /$ day in 2011, and beverages including soda, coffee, and fruit and vegetable drinks are the major source of sugar intake from processed foods in the Korean population. ${ }^{107)}$ For Korean adolescents, carbonated beverages is the number one source of sugar and the consumption of SSBs is on the rise. ${ }^{107,108)}$ For Korean children aged 6-11 years, the mean daily total sugar intake was $79.31 \mathrm{~g} /$ day (boys, $80.00 \mathrm{~g} /$ day; girls, $78.57 \mathrm{~g} /$ day). Children with a beverage intake $\geq 200 \mathrm{~mL} /$ day had a higher total sugar intake $(107.97 \pm 3.24 \mathrm{~g} /$ day vs. $69.13 \pm 1.52 \mathrm{~g} /$ day $) .{ }^{109)}$ Furthermore, $47.9 \%$ of children consuming more than $10 \%$ of their energy intake from total sugar in processed foods. It must be corrected considering the World Health Organization recommendation that the intake of free sugars be less than $10 \%$ of one's total energy intake due to its deleterious health effects. ${ }^{110)}$ The excessive consumption of fructose and sucrose is associated with deleterious effects on the metabolism and an increased risk of visceral adiposity, MetS, NAFLD, IR, and cardiometabolic risk. ${ }^{111-115)}$ No study has directly assessed the association between dietary components and early menarche. However, a meta-analysis suggested that early menarche and insulin resistance are significantly associated; ${ }^{116)}$ thus, it can be inferred that dietary components and early menarche are indirectly related.

Positive associations were also observed between SSB intake and obesity, MetS, NAFLD, insulin resistance, and cardiometabolic risk in Korean women. The OR for obesity in Korean children with a beverage intake of $\geq 200 \mathrm{~mL} /$ day significantly increased by 1.83 times versus that of children with a beverage intake of $<200 \mathrm{~mL} /$ day after the adjustment for confounding variables. ${ }^{109)}$ Korean women who consumed $\geq 4$ servings/week of SSBs were at a significantly higher risk of MetS than infrequent consumers. ${ }^{117)}$ Another Korean cohort study reported that subjects in the highest SSB consumption group were at a significantly greater risk (21\%) of developing hypertension. ${ }^{118)}$

We previously postulated that an excessive consumption of fructose might underlie the development of NAFLD, IR, and MetS. ${ }^{119)}$ Fructose is consumed either as sucrose (50\% fructose) or as high-fructose corn syrup ( $42 \%$ or $55 \%$ fructose). Although both glucose and fructose are categorized as carbohydrates, the hepatic metabolism of fructose is very different to that of glucose in that it is insulin-independent, bypasses the process of glycolysis, and increases de novo lipogenesis to a greater extent; metabolically, fructose is similar to ethanol. ${ }^{120)} \mathrm{SSB}$ consumption was recently reported to be associated with a risk of earlier menarche dose-dependently or -independently of childhood BMI. $^{38,39)}$

\section{Conclusions}

In pediatrics, establishing risk factors is important in planning the prevention of disease in later life. In this review, we showed that early menarche increases the risk of a shorter final height and the development of obesity, IR, MetS, NAFLD, T2DM, breast cancer, and CVD in Korean women as with other ethnicities. Furthermore, a female adolescent with early menarche may suffer from various psychosocial problems and show delinquency and risky sexual behaviors. Although the above mentioned chronic cardiometabolic diseases might occur in adults and should be managed by all physicians, the pediatrician is an advance guard to recognize the problems correlated with early menarche and should take action to prevent its consequences.

We also reviewed the probable mechanism of early menarche: a high fructose intake, in the form of SSB and fruit juice (foods containing no fiber), is one of the major causes of early menarche, obesity, and IR.

A health education program that stresses a healthy diet composed mainly of unprocessed fruits (with much fiber like vegetables) and whole grains, should be implemented. Early menarche might be prevented by lifestyle changes, including regular exercise and a healthy diet (fructose-free and fiber-rich) during infancy and childhood. The secondary prevention of cardiometabolic disease in a female experiencing early menarche involves exercise and a healthy diet in line with obesity management.

We hope that this review will help pediatricians comprehensively understand the lifetime health problems associated with early menarche and to participate in preventing early menarche and its complications.

\section{Conflicts of interest}

No potential conflict of interest relevant to this article was reported. 
Acknowledgments

We thank Sanghui Kweon from the Division of Health and Nutrition Survey for her technical support in analyzing the data of the Korea National Health and Nutrition Examination Survey.

See the commentary "Why should we be concerned about early menarche?" via https://doi.org/10.3345/cep.2020.00521.

\section{References}

1. Sommer M. Menarche: a missing indicator in population health from low-income countries. Public Health Rep 2013;128:399-401.

2. Dvornyk V, Waqar-ul-Haq. Genetics of age at menarche: a systematic review. Hum Reprod Update 2012;18:198-210.

3. Freedman DS, Khan LK, Serdula MK, Dietz WH, Srinivasan SR, Berenson GS. Relation of age at menarche to race, time period, and anthropometric dimensions: the Bogalusa Heart Study. Pediatrics 2002;110:e43.

4. Simondon KB, Simon I, Simondon F. Nutritional status and age at menarche of Senegalese adolescents. Ann Hum Biol 1997;24:521-32.

5. Ahn JH, Lim SW, Song BS, Seo J, Lee JA, Kim DH, et al. Age at menarche in the Korean female: secular trends and relationship to adulthood body mass index. Ann Pediatr Endocrinol Metab 2013;18:60-4.

6. Lee MH, Kim SH, Oh M, Lee KW, Park MJ. Age at menarche in Korean adolescents: trends and influencing factors. Reprod Health 2016;13:121.

7. Cheong JI, Lee CH, Park JH, Ye BJ, Kwon KA, Lee YS, et al. The effect of early menarche on the sexual behaviors of Korean female adolescents. Ann Pediatr Endocrinol Metab 2015;20:130-5.

8. Kang S, Kim YM, Lee JA, Kim DH, Lim JS. Early menarche is a risk factor for short stature in young Korean females: an epidemiologic study. J Clin Res Pediatr Endocrinol 2019;11:234-9.

9. Lee SE, Yang JY, Lee JH, Kim HW, Kim HS, Lee HJ, et al. Relationship of age at menarche on anthropometric index and menstrual irregularity in late adolescent girls in Seoul. Ann Pediatr Endocrinol Metab 2013;18: $116-21$.

10. Lim SW, Ahn JH, Lee JA, Kim DH, Seo JH, Lim JS. Early menarche is associated with metabolic syndrome and insulin resistance in premenopausal Korean women. Eur J Pediatr 2016;175:97-104.

11. Yi KH, Hwang JS, Lim SW, Lee JA, Kim DH, Lim JS. Early menarche is associated with non-alcoholic fatty liver disease in adulthood. Pediatr Int 2017;59:1270-5.

12. Lim JS, Lee HS, Kim EY, Yi KH, Hwang JS. Early menarche increases the risk of type 2 diabetes in young and middle-aged Korean women. Diabet Med 2015;32:521-5.

13. Charalampopoulos D, McLoughlin A, Elks CE, Ong KK. Age at menarche and risks of all-cause and cardiovascular death: a systematic review and meta-analysis. Am J Epidemiol 2014;180:29-40.

14. Sørensen K, Mouritsen A, Aksglaede L, Hagen CP, Mogensen SS, Juul A. Recent secular trends in pubertal timing: implications for evaluation and diagnosis of precocious puberty. Horm Res Paediatr 2012;77:137-45.

15. Euling SY, Herman-Giddens ME, Lee PA, Selevan SG, Juul A, Sørensen TI, et al. Examination of US puberty-timing data from 1940 to 1994 for secular trends: panel findings. Pediatrics 2008;121 Suppl 3:S172-91.

16. Sun SS, Schubert CM, Chumlea WC, Roche AF, Kulin HE, Lee PA, et al. National estimates of the timing of sexual maturation and racial differences among US children. Pediatrics 2002;110:911-9.

17. Euling SY, Selevan SG, Pescovitz OH, Skakkebaek NE. Role of environmental factors in the timing of puberty. Pediatrics 2008;121 Suppl 3: S167-71.

18. Tanner JM. Trend towards earlier menarche in London, Olso, Copenhagen, the Netherlands and Hungary. Nature 1973;243:95-6.

19. Song Y, Ma J, Hu PJ, Zhang B. Geographic distribution and secular trend of menarche in 9-18 year-old Chinese Han girls. Beijing Da Xue Xue Bao
Yi Xue Ban 2011;43:360-4.

20. Cho GJ, Park HT, Shin JH, Hur JY, Kim YT, Kim SH, et al. Age at menarche in a Korean population: secular trends and influencing factors. Eur J Pediatr 2010;169:89-94.

21. Kaprio J, Rimpelä A, Winter T, Viken RJ, Rimpelä M, Rose RJ. Common genetic influences on BMI and age at menarche. Hum Biol 1995;67:73953.

22. Anderson CA, Duffy DL, Martin NG, Visscher PM. Estimation of variance components for age at menarche in twin families. Behav Genet 2007;37:668-77.

23. Ong KK, Elks CE, Li S, Zhao JH, Luan J, Andersen LB, et al. Genetic variation in LIN28B is associated with the timing of puberty. Nat Genet 2009;41:729-33.

24. Perry JR, Stolk L, Franceschini N, Lunetta KL, Zhai G, McArdle PF, et al. Meta-analysis of genome-wide association data identifies two loci influencing age at menarche. Nat Genet 2009;41:648-50.

25. Perry JR, Day F, Elks CE, Sulem P, Thompson DJ, Ferreira T, et al. Parentof-origin-specific allelic associations among 106 genomic loci for age at menarche. Nature 2014;514:92-7.

26. Fisher MM, Eugster EA. What is in our environment that effects puberty? Reprod Toxicol 2014;44:7-14.

27. Ersoy B, Balkan C, Gunay T, Egemen A. The factors affecting the relation between the menarcheal age of mother and daughter. Child Care Health Dev 2005;31:303-8.

28. Tehrani FR, Mirmiran P, Zahedi-Asl S, Nakhoda K, Azizi F. Menarcheal age of mothers and daughters: Tehran lipid and glucose study. East Mediterr Health J 2010;16:391-5.

29. Frisch RE, Revelle R. Height and weight at menarche and a hypothesis of menarche. Arch Dis Child 1971;46:695-701.

30. Lassek WD, Gaulin SJ. Brief communication: menarche is related to fat distribution. Am J Phys Anthropol 2007;133:1147-51.

31. Von Schnurbein J, Moss A, Nagel SA, Muehleder H, Debatin KM, Farooqi IS, et al. Leptin substitution results in the induction of menstrual cycles in an adolescent with leptin deficiency and hypogonadotropic hypogonadism. Horm Res Paediatr 2012;77:127-33.

32. Ong KK, Emmett P, Northstone K, Golding J, Rogers I, Ness AR, et al. Infancy weight gain predicts childhood body fat and age at menarche in girls. J Clin Endocrinol Metab 2009;94:1527-32.

33. Novotny R, Daida YG, Grove JS, Acharya S, Vogt TM. Formula feeding in infancy is associated with adolescent body fat and earlier menarche. Cell Mol Biol (Noisy-le-grand) 2003;49:1289-93.

34. Kwok MK, Leung GM, Lam TH, Schooling CM. Breastfeeding, childhood milk consumption, and onset of puberty. Pediatrics 2012;130: e631-9.

35. Berkey CS, Gardner JD, Frazier AL, Colditz GA. Relation of childhood diet and body size to menarche and adolescent growth in girls. Am J Epidemiol 2000;152:446-52.

36. Koo MM, Rohan TE, Jain M, McLaughlin JR, Corey PN. A cohort study of dietary fibre intake and menarche. Public Health Nutr 2002;5:353-60.

37. Vos MB, Kimmons JE, Gillespie C, Welsh J, Blanck HM. Dietary fructose consumption among US children and adults: the third National Health and Nutrition Examination Survey. Medscape J Med 2008;10:160.

38. Carwile JL, Willett WC, Spiegelman D, Hertzmark E, Rich-Edwards J, Frazier AL, et al. Sugar-sweetened beverage consumption and age at menarche in a prospective study of US girls. Hum Reprod 2015;30:67583.

39. Mueller NT, Jacobs DR Jr, MacLehose RF, Demerath EW, Kelly SP, Dreyfus JG, et al. Consumption of caffeinated and artificially sweetened soft drinks is associated with risk of early menarche. Am J Clin Nutr 2015;102:648-54.

40. Donoso MA, Muñoz-Calvo MT, Barrios V, Garrido G, Hawkins F, Argente J. Increased circulating adiponectin levels and decreased leptin/ soluble leptin receptor ratio throughout puberty in female ballet dancers: association with body composition and the delay in puberty. Eur J Endocrinol 2010;162:905-11.

41. Valentino R, Savastano S, Tommaselli AP, D'Amore G, Dorato M, Lombardi $\mathrm{G}$. The influence of intense ballet training on trabecular bone 
mass, hormone status, and gonadotropin structure in young women. J Clin Endocrinol Metab 2001;86:4674-8.

42. Chavarro J, Villamor E, Narváez J, Hoyos A. Socio-demographic predictors of age at menarche in a group of Colombian university women. Ann Hum Biol 2004;31:245-57.

43. Malina RM. Menarche in athletes: a synthesis and hypothesis. Ann Hum Biol 1983;10:1-24.

44. Rudel RA, Perovich LJ. Endocrine disrupting chemicals in indoor and outdoor air. Atmos Environ (1994) 2009;43:170-81.

45. Diamanti-Kandarakis E, Bourguignon JP, Giudice LC, Hauser R, Prins GS, Soto AM, et al. Endocrine-disrupting chemicals: an Endocrine Society scientific statement. Endocr Rev 2009;30:293-342.

46. Jacobson-Dickman E, Lee MM. The influence of endocrine disruptors on pubertal timing. Curr Opin Endocrinol Diabetes Obes 2009;16:25-30.

47. Leonardi A, Cofini M, Rigante D, Lucchetti L, Cipolla C, Penta L, et al. The effect of bisphenol A on puberty: a critical review of the medical literature. Int J Environ Res Public Health 2017;14:1044.

48. James-Todd T, Terry MB, Rich-Edwards J, Deierlein A, Senie R. Childhood hair product use and earlier age at menarche in a racially diverse study population: a pilot study. Ann Epidemiol 2011;21:461-5.

49. Persson I, Ahlsson F, Ewald U, Tuvemo T, Qingyuan M, von Rosen D, et al. Influence of perinatal factors on the onset of puberty in boys and girls: implications for interpretation of link with risk of long term diseases. Am J Epidemiol 1999;150:747-55.

50. Bertelloni S, Baroncelli GI, Sorrentino MC, Perri G, Saggese G. Effect of central precocious puberty and gonadotropin-releasing hormone analogue treatment on peak bone mass and final height in females. Eur J Pediatr 1998;157:363-7.

51. Klein KO. Precocious puberty: who has it? Who should be treated? J Clin Endocrinol Metab 1999;84:411-4.

52. Onland-Moret NC, Peeters PH, van Gils CH, Clavel-Chapelon F, Key T, Tjønneland A, et al. Age at menarche in relation to adult height: the EPIC study. Am J Epidemiol 2005;162:623-32.

53. Osuch JR, Karmaus W, Hoekman P, Mudd L, Zhang J, Haan P, et al. Association of age at menarche with adult leg length and trunk height: speculations in relation to breast cancer risk. Ann Hum Biol 2010;37:7685.

54. Emons J, Chagin AS, Sävendahl L, Karperien M, Wit JM. Mechanisms of growth plate maturation and epiphyseal fusion. Horm Res Paediatr 2011;75:383-91.

55. Börjesson AE, Lagerquist MK, Windahl SH, Ohlsson C. The role of estrogen receptor $\alpha$ in the regulation of bone and growth plate cartilage. Cell Mol Life Sci 2013;70:4023-37.

56. Harris MA, Prior JC, Koehoorn M. Age at menarche in the Canadian population: secular trends and relationship to adulthood BMI. J Adolesc Health 2008;43:548-54.

57. Freedman DS, Khan LK, Serdula MK, Dietz WH, Srinivasan SR, Berenson GS, et al. The relation of menarcheal age to obesity in childhood and adulthood: the Bogalusa heart study. BMC Pediatr 2003;3:3.

58. Pierce MB, Leon DA. Age at menarche and adult BMI in the Aberdeen children of the 1950s cohort study. Am J Clin Nutr 2005;82:733-9.

59. Mul D, Fredriks AM, van Buuren S, Oostdijk W, Verloove-Vanhorick SP, Wit JM. Pubertal development in The Netherlands 1965-1997. Pediatr Res 2001;50:479-86.

60. van Lenthe FJ, Kemper CG, van Mechelen W. Rapid maturation in adolescence results in greater obesity in adulthood: the Amsterdam Growth and Health Study. Am J Clin Nutr 1996;64:18-24.

61. Demerath EW, Li J, Sun SS, Chumlea WC, Remsberg KE, Czerwinski $\mathrm{SA}$, et al. Fifty-year trends in serial body mass index during adolescence in girls: the Fels Longitudinal Study. Am J Clin Nutr 2004;80:441-6.

62. Tchernof A, Després JP. Sex steroid hormones, sex hormone-binding globulin, and obesity in men and women. Horm Metab Res 2000;32:52636.

63. Choi KM, Kim SM, Kim YE, Choi DS, Baik SH, Lee J, et al. Prevalence and cardiovascular disease risk of the metabolic syndrome using National Cholesterol Education Program and International Diabetes Federation definitions in the Korean population. Metabolism 2007;56:552-8.
64. Gami AS, Witt BJ, Howard DE, Erwin PJ, Gami LA, Somers VK, et al. Metabolic syndrome and risk of incident cardiovascular events and death: a systematic review and meta-analysis of longitudinal studies. J Am Coll Cardiol 2007;49:403-14.

65. Frontini MG, Srinivasan SR, Berenson GS. Longitudinal changes in risk variables underlying metabolic Syndrome X from childhood to young adulthood in female subjects with a history of early menarche: the Bogalusa Heart Study. Int J Obes Relat Metab Disord 2003;27:1398-404.

66. Glueck CJ, Morrison JA, Wang P, Woo JG. Early and late menarche are associated with oligomenorrhea and predict metabolic syndrome 26 years later. Metabolism 2013;62:1597-606.

67. Stöckl D, Meisinger C, Peters A, Thorand B, Huth C, Heier M, et al. Age at menarche and its association with the metabolic syndrome and its components: results from the KORAF4 study. PLoS One 2011;6:e26076.

68. Ahmed ML, Ong KK, Dunger DB. Childhood obesity and the timing of puberty. Trends Endocrinol Metab 2009;20:237-42.

69. Pyörälä M, Miettinen H, Halonen P, Laakso M, Pyörälä K. Insulin resistance syndrome predicts the risk of coronary heart disease and stroke in healthy middle-aged men: the 22-year follow-up results of the Helsinki Policemen Study. Arterioscler Thromb Vasc Biol 2000;20:538-44.

70. Hanley AJ, Williams K, Stern MP, Haffner SM. Homeostasis model assessment of insulin resistance in relation to the incidence of cardiovascular disease: the San Antonio Heart Study. Diabetes Care 2002;25:1177-84.

71. Kaplowitz PB. Link between body fat and the timing of puberty. Pediatrics 2008;121 Suppl 3:S208-17.

72. Angulo P. Nonalcoholic fatty liver disease. NEngl J Med 2002;346:122131.

73. Fabbrini E, Magkos F, Mohammed BS, Pietka T, Abumrad NA, Patterson BW, et al. Intrahepatic fat, not visceral fat, is linked with metabolic complications of obesity. Proc Natl Acad Sci US A 2009;106:15430-5.

74. Targher G, Day CP, Bonora E. Risk of cardiovascular disease in patients with nonalcoholic fatty liver disease. N Engl J Med 2010;363:1341-50.

75. Mueller NT, Pereira MA, Demerath EW, Dreyfus JG, MacLehose RF, Carr JJ, et al. Earlier menarche is associated with fatty liver and abdominal ectopic fat in midlife, independent of young adult BMI: the CARDIA study. Obesity (Silver Spring) 2015;23:468-74.

76. DeFronzo RA. Insulin resistance, lipotoxicity, type 2 diabetes and atherosclerosis: the missing links: the Claude Bernard Lecture 2009. Diabetologia 2010;53:1270-87.

77. Song Y, Manson JE, Tinker L, Howard BV, Kuller LH, Nathan L, et al. Insulin sensitivity and insulin secretion determined by homeostasis model assessment and risk of diabetes in a multiethnic cohort of women: the Women's Health Initiative Observational Study. Diabetes Care 2007;30: 1747-52.

78. Dankner R, Chetrit A, Shanik MH, Raz I, Roth J. Basal-state hyperinsulinemia in healthy normoglycemic adults is predictive of type 2 diabetes over a 24-year follow-up: a preliminary report. Diabetes Care 2009;32: 1464-6.

79. He C, Zhang C, Hunter DJ, Hankinson SE, Buck Louis GM, Hediger ML, et al. Age at menarche and risk of type 2 diabetes: results from 2 large prospective cohort studies. Am J Epidemiol 2010;171:334-44.

80. Dreyfus JG, Lutsey PL, Huxley R, Pankow JS, Selvin E, FernándezRhodes L, et al. Age at menarche and risk of type 2 diabetes among African-American and white women in the Atherosclerosis Risk in Com. munities (ARIC) study. Diabetologia 2012;55:2371-80.

81. Elks CE, Ong KK, Scott RA, van der Schouw YT, Brand JS, Wark PA, et al. Age at menarche and type 2 diabetes risk: the EPIC-InterAct study. Diabetes Care 2013;36:3526-34.

82. Stöckl D, Döring A, Peters A, Thorand B, Heier M, Huth C, et al. Age at menarche is associated with prediabetes and diabetes in women (aged 3281 years) from the general population: the KORA F4 Study. Diabetologia 2012;55:681-8.

83. Mathers CD, Loncar D. Projections of global mortality and burden of disease from 2002 to 2030. PLoS Med 2006;3:e442.

84. Statistics Korea. 2012 Annual report on the cause of death statistics. Daejeon: Statistics Korea, 2013.

85. Luijken J, van der Schouw YT, Mensink D, Onland-Moret NC. Associa- 
tion between age at menarche and cardiovascular disease: a systematic review on risk and potential mechanisms. Maturitas 2017;104:96-116.

86. Kivimäki M, Lawlor DA, Smith GD, Elovainio M, Jokela M, KeltikangasJärvinen L, et al. Association of age at menarche with cardiovascular risk factors, vascular structure, and function in adulthood: the Cardiovascular Risk in Young Finns Study. Am J Clin Nutr 2008;87:1876-82.

87. Mueller NT, Duncan BB, Barreto SM, Chor D, Bessel M, Aquino EM, et al. Earlier age at menarche is associated with higher diabetes risk and cardiometabolic disease risk factors in Brazilian adults: Brazilian Longitudinal Study of Adult Health (ELSA-Brasil). Cardiovasc Diabetol 2014;13:22.

88. Canoy D, Beral V, Balkwill A, Wright FL, Kroll ME, Reeves GK, et al. Age at menarche and risks of coronary heart and other vascular diseases in a large UK cohort. Circulation 2015;131:237-44.

89. Yang L, Li L, Millwood IY, Peters SAE, Chen Y, Guo Y, et al. Age at menarche and risk of major cardiovascular diseases: evidence of birth cohort effects from a prospective study of 300,000 Chinese women. Int J Cardiol 2017;227:497-502.

90. Chang HS, Odongua N, Ohrr H, Sull JW, Nam CM. Reproductive risk factors for cardiovascular disease mortality among postmenopausal women in Korea: the Kangwha Cohort Study, 1985-2005. Menopause 2011;18:1205-12.

91. Won JC, Hong JW, Noh JH, Kim DJ. Association between age at menarche and risk factors for cardiovascular diseases in Korean women: the 2010 to 2013 Korea National Health and Nutrition Examination Survey. Medicine (Baltimore) 2016;95:e3580.

92. Jung KW, Won YJ, Kong HJ, Oh CM, Cho H, Lee DH, et al. Cancer statistics in Korea: incidence, mortality, survival, and prevalence in 2012. Cancer Res Treat 2015;47:127-41.

93. Collaborative Group on Hormonal Factors in Breast Cancer. Menarche, menopause, and breast cancer risk: individual participant meta-analysis, including 118964 women with breast cancer from 117 epidemiological studies. Lancet Oncol 2012;13:1141-51.

94. Gong TT, Wang YL, Ma XX. Age at menarche and endometrial cancer risk: a dose-response meta-analysis of prospective studies. Sci Rep 2015; 5:14051.

95. Jung KJ, Park C, Yun YD, Jee SH. Duration of ovarian hormone exposure and gynecological cancer risk in Korean women: the Korean Heart Study. Cancer Epidemiol 2016;41:1-7.

96. Lakshman R, Forouhi NG, Sharp SJ, Luben R, Bingham SA, Khaw KT, et al. Early age at menarche associated with cardiovascular disease and mortality. J Clin Endocrinol Metab 2009;94:4953-60.

97. Shalitin S, Phillip M. Role of obesity and leptin in the pubertal process and pubertal growth: a review. Int J Obes Relat Metab Disord 2003;27:86974.

98. Argolo DF, Hudis CA, Iyengar NM. The impact of obesity on breast cancer. Curr Oncol Rep 2018;20:47.

99. Andò S, Gelsomino L, Panza S, Giordano C, Bonofiglio D, Barone I, et al. Obesity, leptin and breast cancer: epidemiological evidence and proposed mechanisms. Cancers (Basel) 2019;11:62.

100. Caprio S. Insulin: the other anabolic hormone of puberty. Acta Paediatr Suppl 1999;88:84-7.

101. Apter D, Reinilä M, Vihko R. Some endocrine characteristics of early menarche, a risk factor for breast cancer, are preserved into adulthood. Int J Cancer 1989;44:783-7.

102. Sørensen K, Aksglaede L, Munch-Andersen T, Aachmann-Andersen NJ, Petersen JH, Hilsted L, et al. Sex hormone-binding globulin levels predict insulin sensitivity, disposition index, and cardiovascular risk during puberty. Diabetes Care 2009;32:909-14.

103. Halton TL, Willett WC, Liu S, Manson JE, Stampfer MJ, Hu FB. Potato and french fry consumption and risk of type 2 diabetes in women. Am J Clin Nutr 2006;83:284-90.

104. Lim H, Kim SY, Wang Y, Lee SJ, Oh K, Sohn CY, et al. Preservation of a traditional Korean dietary pattern and emergence of a fruit and dairy dietary pattern among adults in South Korea: secular transitions in dietary patterns of a prospective study from 1998 to 2010. Nutr Res 2014;34:760-70.

105. Shin HY, Kang HT. Recent trends in the prevalence of underweight, overweight, and obesity in Korean adults: the Korean National Health and Nutrition Examination Survey from 1998 to 2014. J Epidemiol 2017;27:413-9.

106. Ministry of Health and Welfare; Korea Centers for Disease Control and Prevention. Korea Health Statistics 2016: Korea National Health and Nutrition Examination Survey (KNHANES VII-1). Cheongju (Korea): Korea Centers for Disease Control and Prevention, 2017.

107. Lee HS, Kwon SO, Yon M, Kim D, Lee JY, Nam J, et al. Dietary total sugar intake of Koreans: based on the Korea National Health and Nutrition Examination Survey (KNHANES), 2008-2011. J Nutr Health 2014;47:268-76.

108. Kim J, Yun S, Oh K. Beverage consumption among Korean adolescents: data from 2016 Korea Youth Risk Behavior Survey. Nutr Res Pract 2019;13:70-5.

109. Wang H, Jeong H, Kim NH, Kang Y, Hwang K, Lee H, et al. Association between beverage intake and obesity in children: the Korea National Health and Nutrition Examination Survey (KNHANES) 2013-2015. Nutr Res Pract 2018;12:307-14.

110. World Health Organization. Guideline: sugars intake for adults and children. Geneva (Switzerland): World Health Organization, 2015.

111. Memon MQ, Kumar A. The fructose mystery: how bad or good is it? Pak J Pharm Sci 2013;26:1241-5.

112. Frost G, Leeds AA, Doré CJ, Madeiros S, Brading S, Dornhorst A. Glycaemic index as a determinant of serum HDL-cholesterol concentration. Lancet 1999;353:1045-8.

113. Elliott SS, Keim NL, Stern JS, Teff K, Havel PJ. Fructose, weight gain, and the insulin resistance syndrome. Am J Clin Nutr 2002;76:911-22.

114. Høstmark AT, Tomten SE. Cola intake and serum lipids in the Oslo Health Study. Appl Physiol Nutr Metab 2009;34:901-6.

115. Ouyang X, Cirillo P, Sautin Y, McCall S, Bruchette JL, Diehl AM, et al. Fructose consumption as a risk factor for non-alcoholic fatty liver disease. J Hepatol 2008;48:993-9.

116. Zhang Z, Hu X, Yang C, Chen X. Early age at menarche is associated with insulin resistance: a systemic review and meta-analysis. Postgrad Med 2019;131:144-50.

117. Kang Y, Kim J. Soft drink consumption is associated with increased incidence of the metabolic syndrome only in women. Br J Nutr 2017; 117:315-24.

118. Kwak JH, Jo G, Chung HK, Shin MJ. Association between sugarsweetened beverage consumption and incident hypertension in Korean adults: a prospective study. Eur J Nutr 2019;58:1009-17.

119. Lim JS, Mietus-Snyder M, Valente A, Schwarz JM, Lustig RH. The role of fructose in the pathogenesis of NAFLD and the metabolic syndrome. Nat Rev Gastroenterol Hepatol 2010;7:251-64.

120. Lustig RH. The fructose epidemic. Bariatrician 2009;24:10.

How to cite this article: Kim JH, Lim JS. Early menarche and its consequence in Korean female: reducing fructose intake could be one solution. Clin Exp Pediatr 2021;64:12-20. https:// doi.org/10.3345/cep.2019.00353 